\title{
CPC Commentary on "Coexistence of cardiac amyloidosis with coronary artery disease and the challenges in medical management"
}

\author{
Lawrence Phillips, $M^{\mathrm{a}}$ \\ a Division of Cardiology, Department of Medicine, NYU Langone Health, New York
}

Received Apr 4, 2019; accepted Apr 4, 2019

doi: $10.1007 / \mathrm{s} 12350-019-01720-0$

\section{See related article, pp. 790-796}

In this issue of the Journal of Nuclear Cardiology, Singh et al present a case of a patient presenting with obstructive coronary artery disease with typical angina who was found to have findings suggestive of cardiac amyloid on imaging. ${ }^{1}$ Both echocardiography and cardiac MRI performed for coronary artery disease related management showed classic findings consistent with cardiac amyloid. Subsequent Tc-PYP imaging supported the diagnosis of TTR amyloid.

There has been tremendous growth over the last several years in the diagnosis of TTR amyloid supported by the use of Tc-PYP imaging. When using a visual grade of 2 or 3 as diagnostic, the sensitivity of Tc-PYP imaging has been found to be $90 \%$ with a specificity of $97 \%$. $^{2}$ This is supported by Practice Points published by the American Society of Nuclear Cardiology which use a visual grade of 2 or greater to be one of the criteria strongly suggestive of TTR amyloid. ${ }^{3}$ The other commonly used criteria of heart to contralateral lung ratio $(\mathrm{H} / \mathrm{Cl})$ will have diagnostic cut offs based on the time between injection and imaging. ${ }^{4}$

As mentioned in the case presentation analysis, prior myocardial infarct should be considered in patients with Tc-PYP cardiac uptake, specifically in those images where the uptake is focal rather than diffuse. ${ }^{5}$ In reporting out the visual interpretation of Tc-PYP, the description of the uptake should note if the uptake is focal, diffuse, or focal on diffuse. ${ }^{3}$

Reprint requests: Lawrence Phillips, MD, Division of Cardiology, Medicine, NYU Langone Health, New York; lawrence.phillips@ nyumc.org

J Nucl Cardiol 2019;26:797

1071-3581/\$34.00

Copyright (C) 2019 American Society of Nuclear Cardiology.
Utilization of Tc-PYP should continue to grow in the nuclear cardiology field as awareness of its excellent sensitivity and specificity expands. Education resulting in high quality imaging and reproducible accurate interpretation will be key for success of this imaging test.

\section{Disclosure}

Lawrence Phillips work was supported by Consultation for Novo Nordisk.

\section{References}

1. Singh V, Tiemeier A, Malhotra SJ. Nucl. Cardiol 2019. https://doi. org/10.1007/s12350-019-01644-9.

2. Gillmore JD, Maurer MS, Falk RH, Merlini G, Damy T, et al. Nonbiopsy diagnosis of cardiac transthyretin amyloidosis. Circulation 2016;133:2404-12.

3. https://www.asnc.org/Files/Practice\%20Resources/Practice\%20Poi nts/ASNC\%20Practice\%20Point-99mTechnetiumPyrophosphateIm aging2016.pdf (accessed April 4, 2019)

4. Bokhari S, Morgenstern R, Weinberg R, Kinkhabwala M, Panagiotou D, Castano A, DeLuca A, Andrew K, Jin Z, Maurer MS. Standardization of ${ }_{99 \mathrm{~m}}$ Technetium pyrophosphate imaging methodology to diagnose TTR cardiac amyloidosis. J Nucl Cardiol 2018;25:181-90.

5. Singh V, Falk R, Di Carli MF, Kijewski M, Rapezzi C, Dorbala S. State-of-the-art radionuclide imaging in cardiac transthyretin amyloidosis. J Nucl Cardiol 2019;26:158-73.

Publisher's Note Springer Nature remains neutral with regard to jurisdictional claims in published maps and institutional affiliations. 